\title{
OKKASIONELLE ANTONYMIE ALS MITTEL DER SPRACHBEREICHERUNG
}

\section{Mowtschan D.}

Kandidat der Philologischen Wissenschaften, Dozentin

ORCID ID 0000-0003-3604-7057

Sumier Staatliche Universität

Sumy, Rymsky-Korsakov Straße, 2

d_movchan@i.ua

\section{Moroz Y.}

Master-Absolventin der Fachrichtung „Übersetzen“,

Sumier Staatliche Universität

Sumy, Rymsky-Korsakov Straße, 2

morozyana96@gmail.com

Eines der Hauptziele der modernen Linguistik ist das Studium der Sprache als universelles Phänomen, das auf solchen Denkfähigkeiten und Denkmechanismen wie Vergleich und Kontrast basiert. Eine solche Manifestation der Besonderheiten des Denkens ist die Fähigkeit des Menschen, Parallelen zu ziehen, die Bedeutung von Begriffen zu versöhnen oder einander gegenüberzustellen.

Von besonderem Interesse in der modernen Linguistik ist die Fähigkeit der Person, implizite Gegensätze zu finden, die nur anhand des spezifischen Kontextes entweder situativ oder sprachlich sichtbar sind. Dieses Phänomen ist als "okkasionelle Antonymie“ bezeichnet.

Der vorliegende Beitrag befasst sich mit der Frage der okkasionellen Antonymie, nämlich mit der Untersuchung deren Potenzials, Sprache zu diversifizieren und zu bereichern. Der Artikel untersucht das Konzept der gelegentlichen Antonymie und identifiziert die wichtigsten Kriterien und Prinzipien, die dieses linguistische Phänomen ermöglichen. Die Studie betrachtet okkasionelle Antonymie nicht nur als ein Sprachbereicherungsmittel, sondern auch als eine Möglichkeit, die Gedanken zu repräsentieren und zu vermitteln. Der Artikel definiert die notwendigen Bedingungen für die sprachliche Gestaltung des untersuchenden Phänomens und beweist die Produktivität der Antonymie als Stilmittel.

Die Grundlage der Forschung bilden moderne Studien im Bereich der Antonymie, die sowohl inländische als auch ausländische Wissenschaftler gemacht haben. Hauptforschungsmaterial sind die biblischen Texte der deutschsprachigen Übersetzung von M. Luther sowie Werke der deutschen Gegenwartsliteratur.

Schlüsselwörter: okkasionelle Antonymie, Bereicherung der Sprache, Bedeutung, Kontext, Gegensatz.

Die Linguistik des XX-XXI Jahrhunderts wird vielseitiger und kontroverser und lässt sich frei mit anderen Wissenschaften kombinieren. Es ermöglicht die bereits etablierten Konzepte und Ideen neu zu betrachten, eine Reihe ungelöster Probleme zu eröffnen und ein großes Feld für die wissenschaftliche Tätigkeit darzustellen.

Daher ist eines der Hauptziele von moderner Linguistik das Studium der Sprache als universelles Phänomens, das auf der Denkfähigkeit und solcher Denkprinzipien wie Vergleich und Opposition beruht.

Eine der Manifestationen von Charakteristiken des Denkens ist die Fähigkeit der Person Parallele zu schaffen, Bedeutungskonzepte $\mathrm{zu}$ approximieren oder sie einander entgegenzusetzen. Von besonderem Interesse ist die Fähigkeit der Person, implizite

(C) Мовчан Д. В., Мороз Я. А., 2019 
Gegensätze zu finden, die nur anhand des spezifischen Kontextes entweder situativ oder sprachlich sichtbar sind. Dieses Phänomen ist als „okkasionelle Antonymie“ bezeichnet.

Der Zweck dieses Artikels ist die Untersuchung der okkasionellen Antonymie als Mittel der Sprachbereicherung und die Bestimmung ihrer Rolle in der Gestaltung und verbaler Widerspiegelung der Realitätspolarisierung nach dem Prinzip der Antithese.

Die Kategorie der Opposition hat bekanntlich logische und philosophische Gründe. Sogar antike Denker (Aristoteles, Demokrit, Platon) und später Philosophen (Hegel, Spinoza, K. Marx, F. Engels) suchten das Wesen des Gegenteils zu verstehen, wenn man diese Kategorie als grundlegend für das Wissen der Welt betrachtet. Die Kategorie der Opposition ist eine universelle Sprachkategorie, die in den Sprachen aller ethnischen Gruppen umgesetzt wird [7].

„Antonymie ist die lexikalische Codierung von negationsinvolvierenden Kontrasten, aufgrund derer sich Wörter interpretatorisch zu Paaren von Gegenwörtern gruppieren. Antonymie ist diejenige Sinn-Relation, die zu ihrer Realisierung - neben der in lexikalischen Primäreinheiten - über das produktivste und reichhaltigste Inventar an Wortbildungsverfahren verfügt. Antonymie ist daher im Prinzip präziser fassbar als andere „-nymie“-Relationen“" $[4$, S. 1]

In der modernen Linguistik werden okkasionelle Antonyme manchmal als kontextuelle sprachliche Einheiten bezeichnet, das heißt, als Wörter, die im Kontext gegenübergestellt sind. L. A. Vvedenskaya achtet auf die mangelnde Einheitlichkeit bei der Definierung gelegentlicher (okkasioneller) Antonyme. Die Autorin schlägt vor, die Doppelkorrelation mit den üblichen Antonymen als das Prinzip der Zuordnung gelegentlicher Antonyme zu betrachten. In Bezug auf die Opposition „Schnee - Ruß“ schreibt sie, z.B., dass es in diesem Paar „eine Art doppelter Korrelation gibt, die sich auf die Farben „weiß-schwarz“ und auf das Vorhandensein einer figurativen Bedeutung „wahrheitsgemäß, ehrlich - schmutzig“ bezieht. Ein solcher Zusammenhang erlaubt es, die Wörter ,Schnee - Ruß “ als gelegentliche Antonyme zu klassifizieren [1, S. 30-31]. Der Lexikologe stellt fest, dass „,der Kohäsionsgrad der Antonyme nicht derselbe ist: In einigen Fällen ist er stabiler, konstanter, in anderen ist er zufällig, episodisch“" 1 , S. 378].

Diese Position von L. A. Vvedenskaya erscheint uns als unabdingbar und kann als Kriterium dafür dienen, die Kategorie der okkasionellen Antonymie zu konstatieren.

Okkasionelle Antonyme sind Wörter, die nur in einem bestimmten Zusammenhang entgegengesetzt sind und aufgrund der Besonderheiten der Sprache und des Stils des Autors neben allgemeingültigen Antonymen, die in den vorhandenen Wörterbücher fixiert sind, existieren [1], z.B.: „Ich - Zar und Knecht, ich - Wurm und Gott! (G. Derzhavin)“.

Es könnte angenommen werden, dass kontextuelle Antonymie keine wesentliche Rolle bei der Bereicherung der Sprache spielen kann, insofern sie nur selten verwendet und reproduziert wird. Trotzdem ist es zu konstatieren, dass solche Situationen von großem Interesse sind. Als Beispiel für ein solches Phänomen dient die Opposition ,Wölfe - Schafe “ (,Es gibt Wölfe und es gibt Schafe“ [10]; „Es gibt drei Arten von Menschen: Schafe, Wölfe und Hütehunde [11]).

Der Wolf als Symboltier taucht in den Projektionen der Menschen als Verkörperung des Schreckens und des Bösen. In der Bibel tritt er als Gegner der Christen und des Christentums auf. Jesus Christus selbst verwendet das Bild des Wolfes:

„Ich bin der gute Hirt. Der gute Hirt gibt sein Leben hin für die Schafe“ (Johannes 10, Vers 11, Bibel).

„Siehe, ich sende euch wie Schafe mitten unter die Wölfe“ (Matthäus 20, Vers 16, Bibel).

„, Seht euch vor den falschen Propheten, die in Schafskleidern zu euch kommen, inwendig aber sind sie reißende Wölfe" (Matthäus 7, Vers 15, Bibel).

Ein Hirt ist derjenige, der seine Tiere hütet. Er muss die Schafe scheren, ihnen bei der Geburt helfen, vor den Wölfen beschützen usw. Ein Hirt kümmert sich um die Tiere, führt sie aber auch ihrer Bestimmung zu. Somit ist Hirt ein Symbol für Gott wie auch für Menschen, die sich um andere Menschen kümmern. 
Aus unserer Sicht kann das lexikalische Paar „Wölfe - Schafe“ als okkasionelle Antonyme interpretiert werden. Dabei lässt sich solche Schlussfolgerung auf die Kollokationstheorie der lexikalischen Bedeutung von J.R. Firths (1957) zurückgehen. Laut J.R. Firths ist die Assoziierung eines Wortes mit dem anderen aufgrund der referentiellen Bedeutung einerseits unvorhersehbar, andererseits können habituelle Assoziationen entstehen, die charakteristisch für den Stil gewisser sozialer Gruppen oder Individuen sind [5].

Ein weiteres Beispiel der okkasionellen Antonymie stellen verbale Konzepte dar, wie, z. B die Opposition "klopfen-auftun", die sich auf reguläre Antonyme "fragen-antworten" beziehen. Durch die Verwendung von kontextabhängigen Antonymen aufgrund ihrer Bildhaftigkeit und Individualität kann der notwendige stilistische Effekt erzielt und damit der gegensätzliche Sinn transponiert werden:

Bitte, so wird euch gegeben; suchet, so werdet ihr finden; klopfet an, so wird euch aufgetan (Matthäus 7, Vers 7, Bibel).

Diese Idee belegt auch die antonymische Opposition "führen-gehen", die eine extrem geringe semantische Divergenz demonstriert, sofern beide lexikalischen Einheiten gesamte Meinung "in eine bestimmte Richtung bewegen" haben, wodurch sie als Synonyme betrachtet werden könnten. Die kontextuelle Umgebung der untersuchten Einheiten erweitert den Rahmen der lexikalischen Bedeutung der Oppositionsmitglieder, verleiht ihnen den gegenteiligen Sinn, und vermittelt das Konzept " in die Falle führen - in die Falle geraten". Somit erhält das lexikalische Paar "führen - gehen" ein starkes Potenzial, um einen stilistischen Effekt zu erzeugen.

Also jemand in das Gefängnis führt, der wird in das Gefängnis gehen; ich möchte mich daher bei Schwert für seine Arbeit und bei Schwert für seine Arbeit bedanken. (Offenbarung 13, Vers 7, Bibel).

Anhand von den Untersuchungen wurde nachgewiesen, dass kontextuelle Antonymie nicht nur durch Vollwörter, sondern auch aufgrund synsemantischer Wortarten, wie Präpositionen realisiert werden kann: , mit mir-gegen mich“.

Wer nicht mit mir ist, der ist gegen mich; wer nicht mit mir sammelt, der zerstreut. (Matthäus 12, Vers 30, Bibel).

Wie es zu sehen ist, tritt in diesem Beispiel noch eine antonymische Opposition des okkasionellen Charakters ,,sammeln-zerstreuen “ auf, die das Konzept „schaffen - zerstören“ repräsentiert.

Es lässt sich anhand unserer Untersuchung schließen, dass kontextuelle Antonymie als vereinfachte Form der Übertragung eines bestimmten Begriffes auf den anderen aufgrund assoziativer Zusammenhänge dient und somit ein notwendiges Bereicherungsmittel der Sprache ist. Dabei erweist sich das Studium von Bibel als vielversprechend, um die theoretischen Grundlagen dieses Phänomens nicht nur aus der philologischen Perspektive, sondern auch vom Standpunkt verwandter Disziplinen, wie Psycholinguistik, Psychologie und Logik zu untersuchen. Eine Fragestellung, die noch weitere Analyse fordern könnte, ist warum bestimmte Gegensätze kontextueller oder situativer Natur als gebräuchliche und hochfrequente Spracheinheiten benutzt werden.

\section{ОКАЗІОНАЛЬНА АНТОНІМІЯ ЯК ЗАСІБ ЗБАГАЧЕННЯ МОВИ}

\section{Мовчан Д. В.}

Кандидат філологічних наук, доцент

ORCID ID 0000-0003-3604-7057

Сумський держаний університет

вул. Римського-Корсакова, 2, м. Суми, Україна

d_movchan@i.ua

Мороз Я. А.

Студентка-магістр

Сумський державний університет 
вул. Римського-Корсакова, 2, м. Суми, Україна morozyana96@gmail.com

Однією з головних цілей сучасної лінгвістики є вивчення мови як універсального явища, щзо будується на здатності до мислення та таких механізмів мислення, як порівняння та протиставлення. Таким проявом особливостей мислення є здатність людини проводити паралелі, зближувати смисли понять або протиставляти їх один одному.

Особливий інтерес для сучасної наукової картини світу представляє здатність людини знаходити неявні протилежності, видимі лише за наявності конкретного контексту, ситуаційного або мовного. Це явище в лінгвістиці отримало назву «оказіональна антонімія». Метою даної статті $\epsilon$ дослідження оказіональноі антонімії як засобу збагачення мови.

У роботі розглянуто питання оказіональної антонімії, а саме досліджено ї потенціал у диверсифікації та збагаченні мови. У статті розкрито поняття оказіональної антонімії та виявлено основні критерії та принципи виникнення досліджуваного явища. Розглянуто антоніми не тільки як засіб збагачення мови, але $i$ як спосіб оформлення та транслювання думки, визначено необхідні умови для ідентифікаиії описуваного явищза та досліджено продуктивність антонімії як стилістичного засобу.

Базисом проведеного дослідження $е$ сучасні итудіі в галузі антонімії як вітчизняних, так $i$ зарубіжних учених. Основним матеріалом дослідження є біблійні тексти німецькомовного перекладу М. Лютера, а також твори сучасної німецькоі художньої літератури.

Окреслено перспективні для проведення наступних досліджень питання, зокрема, з точки зору інших дисциплін, таки, як: психолінгвістика, психологія, логіка, щчо дозволить укріпити актуальні з точки зору сучасної науки міждисциплінарні зв 'язки. Розширення теоретичної бази зазначених дисциилін може позитивно позначитися на вирішенні питань, пов'язаних з функціонуванням мислення та законами людського сприйняття.

Ключові слова: оказіональна антонімія, збагачення мови, значення, контекст, опозичзія.

\section{REFERENZLISTE}

1. Введенская Л. А. Словарь антонимов русского языка. М., 2008, - С. 379.

2. Квартник Я. А., Мовчан Д. В. Критерії визначення контекстуальних антонімів. Актуальні проблеми філології. Матеріали VI Міжнародної науково-практичної конференції. - Херсон: Видавничий дім «Гельветика», 2016. - 152 с.

3. Новиков Л. А. Избранные труды. Т. І. Проблемы языкового значения, М., 2001, $147 \mathrm{c.}$.

4. Lang, Ewald. Antonymie im Lexikon und im Wörterbuch : Projekt D2: Duale Operatoren, Bergische Universität, GHS Wuppertal, Fachbereich 4 Sprach- und Literaturwissenschaften, Wuppertal: Sonderforschungsbereich, 1994. - 282 S.

5. Firths J.R. Papers in Linguistics (1957) London: Oxford University Press.

6. Müller W. Das Gegenwort-Wörterbuch: ein Kontrastwörterbuch mit Gebrauchshinweisen / W. Müller. - Unveränd. Nachdr. der Ausg. von 1998. - Berlin; New York : de Gruyter, 2000. - 580 S.

7. Назаренко О. В., Мовчан Д. В., Чуланова Г. В., Щигло Л. В. Speech norm and its alternation in occasional neologisms/ The role of linguistics and verbal communications in the process of informational support of ethnic originality of nations and their progressive interaction. Peer-reviewed material digest (collective monograph). - London, 2015. - P.19-20 [Elektronische Ressource]. - Zugriff unter: http://gisap.eu/ru/node/82836\#comment-84595. - Datum des Zugangs: 15.12.2018. 
8. Bibel. Altes und neues Testament. [Elektronische Ressource]. - Zugriff unter: https://bibeltext.com/. - Datum des Zugangs: 14.12.2018.

9. Europäische Kulturtage 2006. Literatur. Gawriil Dershawin [Elektronische Ressource]. Zugriff unter: https://kulturtage.blogger.de/stories/441522/. - Datum des Zugangs: 15.12.2018.

10. Spruch des Tages. [Elektronische Ressource]. - Zugriff unter: https://www.spruch-destages.org/lustige-sprueche/1682-es-gibt-schafe-und-es-gibt-woelfe-und-du-bist-einfisch. - Datum des Zugangs: 15.12.2018.

11. Stück: Die Gut-Böse-Dichotomie in „American Sniper“ [Elektronische Ressource]. Zugriff unter: https://hamburgischedramaturgie2punkt0.wordpress.com/2015/04/03/58 stuck-die-gut-bose-dichotomie-in-american-sniper/. - Datum des Zugangs: 15.12.2018.

\section{REFERENCES}

1. Vvedenska L. A. Dictionary of antonyms of the Russian language, - Moscow, 2008. p. 379.

2. Kvartnyk Y.,, Movchan D. Criteria for determining the contextual antonyms. Actual problems of philology. Materials of the VI International Scientific and Practical Conference. - Kherson: Publishing House "Helvetica", 2016. - 152 p.

3. Novikov L. A. Selected Works. T. I. Problems of Linguistic Value. - Moscow, 2001. $147 \mathrm{p}$.

4. Lang, Ewald. Antonymie im Lexikon und im Wörterbuch: Projekt D2: Duale Operatoren, Bergische Universität, GHS Wuppertal, Fachbereich 4 Sprach- und Literaturwissenschaften, Wuppertal: Sonderforschungsbereich, 1994. - 282 S.

5. Firths J.R. Papers in Linguistics (1957) London: Oxford University Press.

6. Müller W. Das Gegenwort-Wörterbuch: ein Kontrastwörterbuch mit Gebrauchshinweisen / W. Müller. - Unveränd. Nachdr. der Ausg. von 1998. - Berlin; New York: de Gruyter, 2000. - 580 S.

7. Nazarenko O. V., Movchan D. V., Chulanova G. V., Shchyhlo L.V. Speech norm and its alternation in occasional neologisms/ The role of linguistics and verbal communications in the process of informational support of ethnic originality of nations and their progressive interaction. Peer-reviewed material digest (collective monograph). - London, 2015. - P.19-20 [Elektronnyi resurs]. - Rezhim dostupu: http://gisap.eu/ru/node/82836\#comment-84595. - Accessed: 15.12.2018.

8. Bibel. Altes und neues Testament. [Elektronnyi resurs]. - Rezhim dostupu: https://bibeltext.com/. - Accessed :14.12.2018.

9. Europäische Kulturtage 2006. Literatur. Gawriil Dershawin [Elektronnyi resurs]. Rezhim dostupu: https://kulturtage.blogger.de/stories/441522/. - Accessed:15.12.2018.

10. Spruch des Tages. [Elektronnyi resurs]. - Rezhim dostupu: https://www.spruch-destages.org/lustige-sprueche/1682-es-gibt-schafe-und-es-gibt-woelfe-und-du-bist-einfisch. - Accessed 15.12.2018.

11. Stück: Die Gut-Böse-Dichotomie in „American Sniper“ [Elektronnyi resurs]. - Rezhim dostupu: https://hamburgischedramaturgie2punkt0.wordpress.com/2015/04/03/58-stuckdie-gut-bose-dichotomie-in-american-sniper/. - Accessed: 15.12.2018.

Received: 26 December, 2018 